\title{
Association between skilled maternal healthcare and postpartum contraceptive use in Ethiopia
}

Gizachew Assefa Tessema ${ }^{1,2^{*}}$, Tensae Tadesse Mekonnen ${ }^{3}$, Zelalem Birhanu Mengesha ${ }^{1,4}$ and Katherine Tumlinson ${ }^{5}$

\begin{abstract}
Background: The postpartum period provides an important opportunity to address unmet need for contraception and reduce short birth intervals. This study aims to assess the association between skilled maternal healthcare and postpartum contraceptive use in Ethiopia.

Methods: Data for this analysis come from the 2011 to 2016 Ethiopian Demographic and Health Surveys (EDHS) and include nearly 5000 married women of reproductive age with a recent birth. Multivariate logistic regression was conducted to investigate the relationship between skilled maternal healthcare and postpartum contraceptive use.

Results: Between rounds of the 2011 and 2016 EDHS, the postpartum contraceptive prevalence increased from 15 to $23 \%$ and delivery in public facilities, use of skilled birth assistance, and skilled antenatal care also grew. In both survey rounds, educated women had approximately twice the odds of postpartum contraceptive use, compared with non-educated women, while an initially significant relationship between wealth and postpartum contraceptive use diminished in significance by 2016. Women with a desire to limit future pregnancy had five to six times the odds of postpartum contraceptive use in both survey rounds, and women in 2016 - unlike those in 2011 - with a desire to delay pregnancy were significantly more likely to use contraception (adjusted odds ratio $(A O R)=4.38,95 \% \mathrm{Cl}$ : 1.46-13.18) compared to women who wanted another child soon. In 2011, no statistically significant associations were found between any maternal healthcare and postpartum contraceptive use. In contrast, in 2016, postpartum contraceptive use was significantly associated with an institutional delivery ( $A O R=1.71,95 \%$ confidence interval (Cl): 1.12-2.62) and skilled antenatal care (AOR $=2.41,95 \% \mathrm{Cl}: 1.41-4.10)$. No significant relationship was observed in either survey round between postpartum contraceptive use and skilled delivery or postnatal care.
\end{abstract}

Conclusions: A comparison of postpartum women in the 2011 and 2016 EDHS reveals increased use of both contraception and skilled maternal healthcare services and improved likelihood of contraceptive use among women with an institutional delivery or antenatal care, perhaps as a result of increased attention to postpartum family planning integration. Additionally, results suggest postpartum women are now using contraception to space future pregnancies, with the potential to help women achieve more optimal birth intervals.

Keywords: Postpartum, Family planning, Maternal healthcare, Ethiopia

\footnotetext{
* Correspondence: agizachew@gmail.com

${ }^{1}$ Department of Reproductive Health, Institute of Public Health, University of Gondar, Gondar, Ethiopia

${ }^{2}$ School of Public Health, The University of Adelaide, Adelaide, Australia

Full list of author information is available at the end of the article
}

(c) The Author(s). 2018 Open Access This article is distributed under the terms of the Creative Commons Attribution 4.0 International License (http://creativecommons.org/licenses/by/4.0/), which permits unrestricted use, distribution, and reproduction in any medium, provided you give appropriate credit to the original author(s) and the source, provide a link to the Creative Commons license, and indicate if changes were made. The Creative Commons Public Domain Dedication waiver (http://creativecommons.org/publicdomain/zero/1.0/) applies to the data made available in this article, unless otherwise stated. 


\section{Background}

Approximately $20 \%$ of births in low-income countries are to women with fewer than 24 months since their previous birth, resulting in a significant number of birth intervals of short duration [1-3]. The critical public health importance of optimal birth intervals for women and children are well-documented. Birth intervals spanning two to five years are associated with improved child nutrition, reduced likelihood of preterm birth and low birth weight, and - subsequently - increased child survival [4-6]. Optimal child spacing may also reduce the likelihood of abortion, miscarriage, and stillbirth and reduces competition among siblings [1, 7]. In addition to these benefits for children and infants, women with healthy birth intervals are at reduced risk of maternal death and pregnancy-related morbidity [8]. As such, family planning programs have great potential to reduce maternal, child, and infant mortality in developing country settings by helping women achieve healthy birth intervals. Experts estimate nearly one third of all maternal deaths and close to $10 \%$ of deaths to children under five years of age could be averted by eliminating short birth intervals $[4,9]$.

One key strategy for ensuring optimal birth intervals is the promotion of contraceptive use in the postpartum period [1]. Evidence suggests that the vast majority of women in developing countries wish to avoid pregnancy in the first year following a birth, but unmet need within this vulnerable group is consistently higher than in women outside of the extended postpartum period; some estimates of unmet need in the extended postpartum period are as high as $65 \%$ [10-13]. A variety of reasons may contribute to unmet need among postpartum women; yet several studies conducted in countries in Africa and Asia have demonstrated that use of maternal health services, such as pre- and postnatal care and institutional delivery, can enhance postpartum family planning use [14-18]. Therefore, the postpartum period provides a unique and critical opportunity to fulfil unmet need for contraceptives and to reduce the risks of closely spaced pregnancies [13]. Integration of family planning counselling with pre- and postpartum services has the potential to help motivated women achieve adequate birth spacing as well as limit unintended pregnancy. A recent study provides compelling evidence that the provision of information on family planning to women in the postpartum period resulted in significantly increased contraceptive use [19].

Ethiopia has a total population of 95 million people, nearly one quarter of which are women of reproductive age. The catchment area of primary health care facilities (public hospitals, health centres, and health posts) covers nearly $92 \%$ of the population [20]. Despite the potential to reach a vast majority of the Ethiopian population, in reality, a much smaller portion of the population utilise skilled maternal healthcare services in Ethiopia: in 2016, $26 \%$ of pregnant women delivered in a health facility, $62 \%$ of pregnant women received skilled antenatal care, and $17 \%$ received skilled postnatal care [21]. The current prevalence of modern contraceptive use in Ethiopia is approximately $25 \%$ of all women of reproductive age and $35 \%$ of married women of reproductive age; nearly one out of every four married women of reproductive age has an unmet need for family planning [21, 22]. An analysis of birth intervals in 44 low-income countries found $46 \%$ of parous women sampled in the 2005 Ethiopia Demographic and Health Survey (EDHS) reported birth intervals of less than two years. In comparison, among the 25 other African countries included in the analysis, the percent of women with a birth interval under two years ranged from 24 to $54 \%$ and, when compared with Ethiopia, only four African countries had a larger percentage of women with birth intervals under two years [5].

The 2011 Ethiopian national guidelines for family planning services mandate integration of family planning services with all skilled maternal healthcare services [23]. Government health policies also aim to increase the contraceptive prevalence rate among married women of reproductive age to $55 \%$ and to reduce unmet need to $10 \%$ by 2020 [24]. One key and promising national strategy being implemented in an effort to achieve these targets is promotion of postpartum contraceptive use through the scale-up of existing postpartum family planning services by expanding the services to district level health facilities and universal access of contraceptive methods in the immediate postpartum period in 2020 $[24,25]$. Towards this end, additional information is needed to better understand whether use of skilled maternal healthcare services such as pre- and postnatal care and institutional delivery might impact subsequent postpartum contraceptive use in Ethiopia.

The present study uses large scale national datasets collected in 2011 and 2016 to examine the association between use of skilled maternal healthcare services and subsequent postpartum contraceptive use among married reproductive aged women in Ethiopia, and compares the findings between the two surveys. The findings of this study can inform policies and programs designed to improve postpartum family planning use, reduce unmet need, and reduce the prevalence of short birth intervals among Ethiopian women.

\section{Methods}

Study design and sample

The Ethiopian Demographic and Health Survey (EDHS) was first implemented in Ethiopia in 2000 and a total of four national surveys have been conducted as of 2016 . 
The present analysis uses data from the latest two rounds of the EDHS, collected in 2011 and 2016. The EDHS is a cross-sectional survey conducted every five to six years to measure the demographic and health-related characteristics of the population [26]. The EDHS 2011 survey was conducted from December 2010 to June 2011 and includes interviews with a total of 16,515 women of reproductive age [27]. The EDHS 2016 survey was conducted from January to June 2016 and includes a sample of 15,683 women of reproductive age [21]. A stratified, two-stage cluster sampling procedure was used to recruit the nationally representative sample in both surveys. The 11 administrative regions found in Ethiopia were initially stratified into urban and rural areas. Each stratum was subdivided into districts (woredas), and woredas were then subdivided into kebeles (the smallest administrative unit in Ethiopia). Finally each kebele was subdivided into Enumeration Areas (EAs) that served as sampling clusters. A total of 624 EAs were included in EDHS 2011 and 645 EAs were included in EDHS 2016. In the present analysis, we included married/in sexual union, non-pregnant women who gave birth in the 12 months prior to data collection. As a result, a total of $2545 \mathrm{married} /$ in sexual union women in EDHS 2011 and $2386 \mathrm{married} /$ in sexual union women in EDHS 2016 were included in our final analysis (Fig. 1). The analysis was restricted to married/in sexual union women to allow cross-country comparisons of contraceptive prevalence rate $(\mathrm{CPR})$, which is often calculated only for married women and those in sexual union. Additionally, we excluded women who were not married or in sexual union because they are not considered at risk for pregnancy and therefore do not require methods of pregnancy prevention, the main outcome of interest in this analysis.

\section{Postpartum contraceptive use}

In this analysis the dependent variable is a binary variable for postpartum contraceptive use. Postpartum contraceptive use is defined as any self-reported use of a modern contraceptive method (modern methods reported in this sample included: female sterilization, implant, intrauterine device (IUD), injectable, oral contraceptive, emergency contraceptive, lactational amenorrhea method (LAM) or condom) at the time of data collection. Those women not reporting any modern method use and those reporting traditional method use (periodic abstinence or withdrawal) were classified as non-users.

\section{Skilled maternal healthcare services}

We examined the association between postpartum contraceptive use and four key maternal healthcare services, all coded as binary variables: institutional delivery, presence of a skilled birth attendant, skilled antenatal care, and skilled postnatal care. Institutional delivery was classified based on the place of delivery. A woman was defined as having an institutional delivery if she had given birth (the most recent time) at a hospital, health centre, or any private facility; otherwise women were classified as having a home delivery. Skilled attendance at birth was based on who attended the delivery irrespective of the place of delivery. Those women whose most recent birth was attended by a professional (doctor, midwife or nurse, health officer) possessing midwifery skills were classified as having skilled attendance at birth. Skilled antenatal care included any woman receiving one or more episodes of antenatal care by a skilled provider. Skilled postnatal care was based on health check-ups by skilled professionals (doctor, midwife or nurse, health officer) for women who

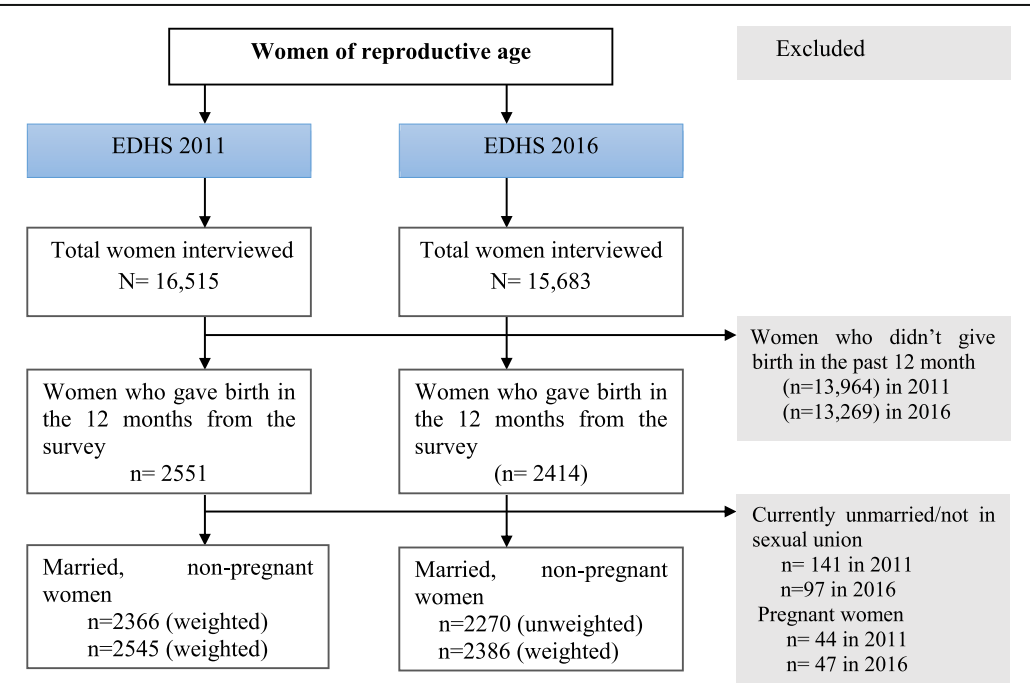

Fig. 1 Schematic presentation showing sampling in the 2011 and 2016 Ethiopia Demographic and Health Surveys (EDHS) 
delivered in a health facility or at home within the first six weeks of the participant's most recent delivery.

\section{Demographic and reproductive and maternal health variables}

Demographic, reproductive health and other factors were also examined as potential covariates in this analysis. Demographic variables include age, rural versus urban residence, region, religion, participant's education, partner's education, employment status, wealth, and parity. Reproductive health and other factors include birth order, concordant family planning preferences, fertility preferences, women's decision-making, contraceptive knowledge (the ability to mention at least one method), any visit from a family planning worker in the last 12 months, and exposure to family planning media messages (newspaper, radio, television, or mobile SMS text) in the last few months. Women's decision making was defined by whether a woman reports that she can make decisions by herself or jointly with her partner about the following: decisions about health service utilisation, decisions about household purchases, and decisions to visit family or relatives. Specific categories for these variables are shown in Tables 1, 2, and 3 .

\section{Statistical analysis}

We used STATA version 14.0 to conduct all the analysis. Descriptive statistics were calculated for all variables described above. Multivariate logistic regression was conducted to estimate adjusted odds ratios. Those demographic and reproductive health variables described above which had a $p$-value of less than 0.2 in the binary logistic regression analysis were included as covariates in our model. During EDHS 2011, some areas were oversampled in order to have regional estimates. Additionally, non-response was observed in the survey. In order to ensure the actual representativeness of survey results at the national level, all analyses in the present study were weighted. The complete sample weight computation is available with the dataset provided by ICF International.

\section{Results}

\section{Socio-demographic characteristics}

This analysis includes nearly 5000 married/in sexual union women of reproductive age with a birth in the 12 months preceding the survey; 2545 of these women participated in the 2011 EDHS while the remaining 2386 were participants in the 2016 survey. As seen in Table 1, about half of all women (47\% in 2011 and 50\% in 2016) were between the ages of 25 and 34, with a median age of 28 years. The majority of the respondents $(87 \%$ in 2011 and 88\% in 2016) were rural residents. Oromo and Amhara ethnic groups were the predominant groups in both rounds of the EDHS. With regard to the level of education, the proportion of women who did not have any formal education decreased from $67 \%$ in 2011 to $59 \%$ in 2016 and the proportion of women who completed secondary education more than doubled between surveys (4\% in 2011 to $9 \%$ in 2016). Likewise, the proportion of participants whose partners completed secondary education nearly doubled between surveys from 9 to $15 \%$. About $53 \%$ of these postpartum women were not working outside the home. When looking at the household wealth, $46 \%$ of participants in both surveys were in the poorest group, with no change between surveys in terms of the distribution of wealth.

\section{Reproductive health characteristics of women in the postpartum period}

As shown in Table 2, in both surveys, more than a third of women had between one and two children, more than a fourth had three to four children, and nearly a third had five or more children. For the majority of participants (80 to $85 \%$ ), their most recent birth was not their first birth, although first-time deliveries increased by about $5 \%$ when comparing the 2011 and 2016 samples. Few changes were seen between surveys in terms of family size concordance, with just about $40 \%$ of couples agreeing on ideal family size and approximately one in four women reporting that their partner wants a bigger family than they do. In both surveys, fertility preferences remained approximately stable, with only about six to 8 $\%$ of women reporting a desire for another child soon; about one third reported not wanting any more children and more than half reported wishing to delay their next pregnancy. Ability to mention at least one contraceptive method remained nearly universal in both survey rounds and exposure to family planning media messages stayed stable at around $25 \%$. Notably, the percentage of women reporting some degree of decision-making power increased from 50 to $68 \%$. Also of note, the percentage of women who reported a visit by a family planning worker in the preceding 12 months doubled between surveys from 16 to $33 \%$.

\section{Postpartum contraceptive and skilled maternal healthcare utilisation}

In the last five years, the prevalence of contraceptive use increased by $53 \%$ from $15 \%$ in 2011 to $23 \%$ in 2016 (Table 3). In terms of the contraceptive method mix in both surveys, injectable contraception was the predominant method (Fig. 2). While there were little to no changes in the contribution to the national method mix by pills, female sterilization, condoms, and LAM, there was a notable change in the contribution of implants (10\% in 2011 vs $16 \%$ in 2016$)$ and IUD (1\% in 2011 vs $4 \%$ in 2016) (Fig. 2). 
Table 1 Sociodemographic characteristics in the 2011 and 2016 Ethiopia Demographic and Health Surveys (EDHS), among married/in sexual union women of reproductive age

\begin{tabular}{|c|c|c|c|c|}
\hline \multirow[t]{2}{*}{ Variables } & \multicolumn{2}{|l|}{$\begin{array}{l}\text { EDHS 2011 } \\
(N=2545)\end{array}$} & \multicolumn{2}{|l|}{$\begin{array}{l}\text { EDHS } 2016 \\
(N=2386)\end{array}$} \\
\hline & Frequency & Percent & Frequency & Percent \\
\hline \multicolumn{5}{|l|}{ Age in years } \\
\hline $15-24$ & 833 & 32.7 & 745 & 31.2 \\
\hline $25-34$ & 1203 & 47.3 & 1194 & 50.0 \\
\hline $35+$ & 509 & 20.0 & 447 & 18.7 \\
\hline Mean age (SD) & $27.68( \pm 6.5)$ & & $27.63(6.3)$ & \\
\hline \multicolumn{5}{|l|}{ Place of residence } \\
\hline Urban & 332 & 13.1 & 287 & 12.0 \\
\hline Rural & 2213 & 86.9 & 2099 & 88.0 \\
\hline \multicolumn{5}{|l|}{ Region } \\
\hline Tigray & 139 & 5.5 & 168 & 7.0 \\
\hline Affar & 22 & 0.9 & 23 & 1.0 \\
\hline Amhara & 543 & 21.3 & 449 & 18.8 \\
\hline Oromiya & 1136 & 44.6 & 1041 & 43.6 \\
\hline Somali & 79 & 3.1 & 114 & 4.8 \\
\hline Benishangul-Gumuz & 29 & 1.1 & 26 & 1.1 \\
\hline $\begin{array}{l}\text { Southern Nation, } \\
\text { Nationalities and People } \\
\text { Region }\end{array}$ & 525 & 20.6 & 488 & 20.4 \\
\hline Gambela & 7 & 0.3 & 5 & 0.2 \\
\hline Harari & 6 & 0.2 & 6 & 0.3 \\
\hline Addis Ababa & 53 & 2.1 & 58 & 2.4 \\
\hline Dire Dawa & 8 & 0.3 & 9 & 0.4 \\
\hline \multicolumn{5}{|l|}{ Religion } \\
\hline Orthodox & 908 & 35.7 & 792 & 33.2 \\
\hline Muslim & 979 & 38.5 & 1042 & 43.7 \\
\hline Protestant & 586 & 23.0 & 475 & 19.9 \\
\hline Other/missing & 72 & 2.8 & 78 & 3.3 \\
\hline \multicolumn{5}{|l|}{ Highest educational status } \\
\hline None & 1703 & 66.9 & 1417 & 59.4 \\
\hline Primary & 745 & 29.3 & 755 & 31.6 \\
\hline Secondary+ & 97 & 3.8 & 215 & 9.0 \\
\hline \multicolumn{5}{|l|}{ Partner highest educational status } \\
\hline None & 1223 & 48.0 & 1056 & 44.3 \\
\hline Primary & 1100 & 43.2 & 969 & 40.6 \\
\hline Secondary+ & 223 & 8.7 & 361 & 15.1 \\
\hline \multicolumn{5}{|l|}{ Women occupation } \\
\hline Not working & 1355 & 53.2 & 1476 & 61.9 \\
\hline $\begin{array}{l}\text { Working but not paid/paid } \\
\text { in kind only }\end{array}$ & 512 & 20.1 & 585 & 24.5 \\
\hline paid with cash & 678 & 26.6 & 326 & 13.7 \\
\hline \multicolumn{5}{|l|}{ Wealth index } \\
\hline Low & 1160 & 45.6 & 1085 & 45.5 \\
\hline
\end{tabular}

Table 1 Sociodemographic characteristics in the 2011 and 2016 Ethiopia Demographic and Health Surveys (EDHS), among married/in sexual union women of reproductive age (Continued)

\begin{tabular}{|c|c|c|c|c|}
\hline \multirow[t]{2}{*}{ Variables } & \multicolumn{2}{|l|}{$\begin{array}{l}\text { EDHS } 2011 \\
(N=2545)\end{array}$} & \multicolumn{2}{|l|}{$\begin{array}{l}\text { EDHS } 2016 \\
(N=2386)\end{array}$} \\
\hline & Frequency & Percent & Frequency & Percent \\
\hline Middle & 539 & 21.2 & 491 & 20.6 \\
\hline High & 846 & 33.2 & 810 & 33.9 \\
\hline
\end{tabular}

With respect to maternal healthcare, while only about one in ten women reported delivery in a health facility in 2011, more than a third of our 2016 sample reported delivery in a health facility. Use of public facilities became nearly universal within our 2016 sample, as compared to private facility use, among those women not delivering at home. Additionally we observed a threefold increase in the use of skilled assistance during delivery and a twofold increase in the number of women receiving skilled antenatal care, when comparing the two survey samples. We also observed modest increases in the number of women with four or more antenatal visits and skilled postnatal care (Table 3).

\section{Factors associated with postpartum contraceptive use}

In our 2011 sample of postpartum women, two demographic characteristics were strongly associated with postpartum family planning. Women in the highest wealth category had nearly three times the odds of postpartum contraceptive use compared to women in the lowest wealth category. In addition to wealth, education was strongly associated with postpartum contraceptive use in the 2011 sample; those with at least a primary education were nearly twice as likely to use contraception, compared to women with no education. In our 2016 sample of postpartum women, education remains associated with contraceptive use but the magnitude of the association between wealth and family planning use is greatly reduced and the result is only marginally significant (Tables 4 and 5).

In the 2011 sample of postpartum women, the strongest association with postpartum contraceptive use was seen among women who reported a desire to avoid future pregnancy. Women who wanted no more children had six times the odds of postpartum contraceptive use compared to women who would like to have a child soon. We did not find any relationship between women with a desire to delay pregnancy and contraceptive use in our 2011 sample of women. In the 2016 data, our sample of women also demonstrated a strong likelihood to use contraception in the postpartum period if they preferred no more children; in contrast with the 2011 data however, our 2016 sample of women were also significantly more likely to use contraception if they had a 
Table 2 Reproductive health related characteristics in the 2011 and 2016 Ethiopia Demographic and Health Surveys (EDHS), among married/in sexual union women of reproductive age

\begin{tabular}{|c|c|c|c|c|}
\hline \multirow[t]{2}{*}{ Variables } & \multicolumn{2}{|c|}{ EDHS $2011(N=2545)$} & \multicolumn{2}{|c|}{ EDHS $2016(N=2386)$} \\
\hline & Frequency & Percent & Frequency & Percent \\
\hline
\end{tabular}

Number of living children

$\begin{array}{lllll}\text { No child } & 24 & 0.9 & 15 & 0.6 \\ 1-2 \text { child } & 942 & 37.0 & 939 & 39.4 \\ 3-4 \text { child } & 746 & 29.3 & 653 & 27.4 \\ 5+ & 834 & 32.8 & 780 & 32.7\end{array}$

Birth order

$\begin{array}{lllll}\text { First } & 393 & 15.4 & 480 & 20.1 \\ 2-3 \text { birth } & 848 & 33.3 & 749 & 31.4 \\ 4-5 \text { birth } & 565 & 22.2 & 510 & 21.4 \\ 6+ & 739 & 29.0 & 647 & 27.1\end{array}$

Family size concordance

$\begin{array}{lllll}\text { Both want same } & 982 & 38.6 & 998 & 41.8 \\ \text { Husband wants more } & 662 & 26.0 & 580 & 24.3 \\ \text { Husbands wants fewer } & 187 & 7.4 & 147 & 6.1 \\ \text { Do not know/Missing } & 714 & 28.1 & 662 & 27.7\end{array}$

Fertility preference

$\begin{array}{lllll}\text { wants soon } & 151 & 5.9 & 187 & 7.8 \\ \text { wants later } & 1387 & 54.5 & 1298 & 54.4 \\ \text { wants no more } & 892 & 35.1 & 760 & 31.9 \\ \text { Undecided } & 115 & 4.5 & 142 & 5.9\end{array}$

Women's decision-making ${ }^{\mathrm{b}}$

$\begin{array}{lllll}\text { Yes } & 1272 & 50.0 & 1623 & 68.0 \\ \text { No } & 1273 & 50.0 & 764 & 32.0\end{array}$

Knowledge of modern contraceptive

$\begin{array}{lllll}\text { Yes } & 2463 & 96.8 & 2351 & 98.5 \\ \text { No } & 82 & 3.2 & 35 & 1.5\end{array}$

Visited by FP worker in the last 12 months

$\begin{array}{lllll}\text { Yes } & 416 & 16.3 & 778 & 32.6 \\ \text { No } & 2129 & 83.7 & 1608 & 67.4\end{array}$

Exposure to family planning media ${ }^{a}$

\begin{tabular}{lllll} 
Yes & 689 & 27.1 & 592 & 24.8 \\
No & 1856 & 72.9 & 1794 & 75.2 \\
\hline
\end{tabular}

${ }^{a}$ Exposure to family planning media was determined by whether a woman reported she has heard/read about family planning from radio/television/ newspaper/ mobile SMS. ' Women's decision-making was defined by whether a woman reported that she herself has made decisions (or made a joint decision with her partner) about her own health care, large household purchase, or visiting families/relatives

desire to delay a future pregnancy (AOR: 4.38, 95\% CI: 1.46 - 13.18) (Tables 4 and 5).

Regarding use of skilled maternal healthcare, no statistically significant associations were found in the 2011 sample of women. Women who delivered in a health facility or with a skilled attendant were no more likely
Table 3 Maternal healthcare services related characteristics in the 2011 and 2016 Ethiopia Demographic and Health Surveys (EDHS), among married/in sexual union women of reproductive

\begin{tabular}{|c|c|c|c|c|}
\hline \multirow[t]{2}{*}{ Variables } & \multicolumn{2}{|l|}{$\begin{array}{l}\text { EDHS } 2011 \\
(N=2545)\end{array}$} & \multicolumn{2}{|l|}{$\begin{array}{l}\text { EDHS 2016 } \\
(N=2386)\end{array}$} \\
\hline & Frequency & $\overline{\text { Percent }}$ & Frequency & Percent \\
\hline \multicolumn{5}{|l|}{ Current contraceptive use } \\
\hline Yes & 378 & 14.9 & 553 & 23.2 \\
\hline No & 2167 & 85.1 & 1834 & 76.8 \\
\hline \multicolumn{5}{|l|}{ Place of delivery } \\
\hline Home & 2272 & 89.3 & 1499 & 62.8 \\
\hline Health facility & 273 & 10.7 & 887 & 37.2 \\
\hline \multicolumn{5}{|c|}{ Place of delivery by facility type ${ }^{a}$} \\
\hline Public facility & 234 & 85.7 & 864 & 97.4 \\
\hline Private facility & 39 & 14.3 & 23 & 2.6 \\
\hline \multicolumn{5}{|l|}{ Who assisted delivery } \\
\hline $\begin{array}{l}\text { No assistance/ assisted by } \\
\text { unskilled provider }\end{array}$ & 2221 & 87.2 & 1478 & 62.0 \\
\hline Doctor & 29 & 1.2 & 99 & 4.1 \\
\hline Nurse/midwife/HO & 295 & 11.6 & 809 & 33.9 \\
\hline \multicolumn{5}{|l|}{ Skilled ANC } \\
\hline Yes & 820 & 32.2 & 1620 & 67.8 \\
\hline No & 1725 & 67.8 & 766 & 32.7 \\
\hline \multicolumn{5}{|c|}{ Number of skilled $\operatorname{ANC}^{\mathrm{b}}(n=820)$} \\
\hline One times & 117 & 14.3 & 126 & 7.8 \\
\hline 2-3 times & 356 & 43.4 & 677 & 41.8 \\
\hline $4+$ times & 347 & 42.3 & 817 & 50.4 \\
\hline \multicolumn{5}{|l|}{ Skilled PNC use } \\
\hline Yes & 183 & 7.18 & 455 & 19.1 \\
\hline No PNC & 2362 & 92.18 & 1931 & 80.9 \\
\hline
\end{tabular}

ANC Antenatal care, PNC Postnatal care, $\mathrm{HO}$ Health officer

${ }^{a} n=$ calculated from facility delivery, ${ }^{b} n=$ calculated from those who received skilled ANC

than women with home births or those without skilled attendance to use postpartum family planning. Similarly, women with antenatal care visits were no more likely to use postpartum family planning than those without such visits. We found only a marginally significant relationship between postnatal care and postpartum contraceptive use in the 2011 data. In contrast, delivery within a health facility as well as obtaining skilled antenatal care are both significantly associated with postpartum contraceptive use in the 2016 sample, with adjusted odds ratios of 1.71 (95\% CI: 1.12-2.62) and 2.41 (95\% CI: 1.41-4.10) respectively (Tables 4 and 5 ).

\section{Discussion}

This study describes the prevalence of postpartum contraceptive use and skilled maternal healthcare among 


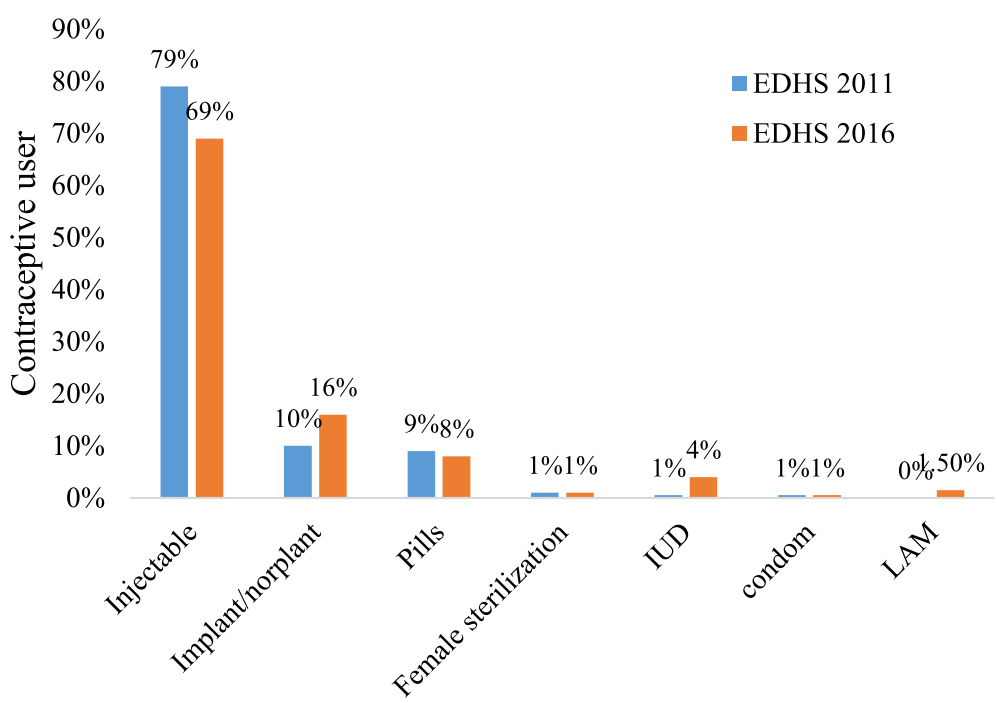

Fig. 2 Contraceptive method mix among postpartum women using modern contraceptive methods in $2011(n=378)$ and $2016(n=553)$ in the Ethiopia Demographic and Health Surveys (EDHS)

two representative samples (collected in 2011 and 2016) of married/in sexual union women in Ethiopia with a birth in the previous year. Our findings in both rounds are far lower than a finding from similar study in Indonesia (74\%) [28]. In our 2011 sample, we found low contraceptive use; only $15 \%$ of women were protected from early pregnancy. This is much lower than the overall prevalence of modern method use reported by married women in the 2011 EDHS (approximately 27\%), despite the increased health risks to women in the postpartum period [29]. Contraceptive use was much higher (23\%) in our 2016 sample of married/in sexual union postpartum women, although still not keeping pace with the overall prevalence of modern method use among all married women of reproductive age in Ethiopia (35\% in the 2016 EDHS). Additionally, when compared with the 2011 sample, women in our 2016 sample reported a higher prevalence of facility delivery, greater use of public facilities for delivery, higher prevalence of skilled assistance during delivery (especially nurse and midwife assistance), and a higher prevalence of receiving skilled ante- and postnatal care. In fact, the proportion of women reporting skilled birth assistance or pre- or postnatal care more than doubled and institutional births more than tripled during the five-year period. This growth between 2011 and 2016 in the prevalence of both contraceptive use and skilled maternal healthcare suggests government efforts to increase access to and use of these services are rapidly succeeding. However, the remaining large numbers of women giving birth at home and/or without assistance and without skilled postpartum care indicate the need for these efforts to continue.
In addition to increased uptake of both contraception and skilled maternal healthcare, we also noted a shift in the role played by both wealth and fertility intentions. In the 2011 data, residing in the highest wealth category was strongly associated with an increased likelihood of postpartum contraceptive use. In other words, among women in the 2011 sample, wealthier women were nearly three times more likely to use contraception compared to women in the lowest wealth category. This finding is consistent with studies conducted throughout Africa which have found that wealthier women were more likely to be using contraception compared to their poorer counterparts $[17,18,30]$. Although family planning services in Ethiopia are offered free of charge in public facilities, this finding could reflect indirect costs, such as transportation, which may prohibit access to family planning services. In the 2016 data however, wealth was only marginally significant in terms of its relationship with postpartum contraceptive use, with an adjusted odds ratio of far less magnitude (1.5 compared to 2.7 in 2011). This finding suggests that wealth may play a much smaller role in women's postpartum contraceptive behaviour compared to five years ago, perhaps as a result of increased outreach efforts; indeed, the proportion of participants reportedly visited by a family planning worker in the 12 months preceding the survey doubled between survey rounds. This finding is a promising indication that the prevalence of contraceptive use is not only rising, but that it is growing in ways that promote greater health equity.

Additionally, we saw in the 2011 data that women who didn't want any more children were significantly more likely to use family planning, compared to women 
Table 4 Multivariate logistic regression examining factors associated with postpartum contraceptive use in Ethiopia, $2011(n=2545)$

\begin{tabular}{|c|c|c|c|c|c|c|}
\hline \multirow[t]{2}{*}{ Variables } & \multicolumn{2}{|c|}{ PPFP Use } & \multicolumn{4}{|c|}{ OR $(95 \% \mathrm{Cl})$} \\
\hline & No & Yes & COR & $95 \% \mathrm{Cl}$ & $\mathrm{AOR}$ & $95 \% \mathrm{Cl}$ \\
\hline \multicolumn{7}{|l|}{ Wealth index } \\
\hline Low & 1091 & 69 & 1 & & 1 & \\
\hline Middle & 479 & 61 & 2.01 & $1.16-3.50$ & 1.55 & $0.89-2.72$ \\
\hline High & 597 & 249 & 6.61 & $4.20-10.39$ & $2.74^{* * *}$ & $1.53-4.92$ \\
\hline \multicolumn{7}{|l|}{ Age category (in years) } \\
\hline $15-24$ & 642 & 191 & 1 & & 1 & \\
\hline $25-34$ & 1055 & 148 & 0.47 & $0.32-0.69$ & 0.82 & $0.51-1.31$ \\
\hline $35+$ & 470 & 39 & 0.27 & $0.17-0.46$ & 0.75 & $0.32-1.76$ \\
\hline \multicolumn{7}{|l|}{ Residence } \\
\hline Urban & 186 & 147 & 6.77 & $4.55-10.07$ & 1.89 & $0.93-3.84$ \\
\hline Rural & 1981 & 231 & 1 & & 1 & $0.27-1.13$ \\
\hline \multicolumn{7}{|c|}{ Access to family planning media } \\
\hline No & 1654 & 203 & 1 & & 1 & \\
\hline Yes & 513 & 175 & 2.79 & $1.94-4.00$ & 1.41 & $0.91-2.18$ \\
\hline \multicolumn{7}{|l|}{ Women educational status } \\
\hline No education & 1564 & 139 & 1 & & 1 & \\
\hline Primary & 547 & 198 & 4.07 & $2.92-5.68$ & $1.83^{*}$ & $1.22-2.77$ \\
\hline Secondary or above & 56 & 41 & 8.19 & $4.15-16.17$ & 1.02 & $0.42-2.48$ \\
\hline \multicolumn{7}{|l|}{ Partner education } \\
\hline No education & 1120 & 102 & 1 & & 1 & \\
\hline Primary & 893 & 207 & 2.54 & $1.67-3.84$ & 1.23 & $0.73-2.06$ \\
\hline Secondary or above & 154 & 69 & 4.92 & $2.69-8.99$ & 0.62 & $0.27-1.40$ \\
\hline \multicolumn{7}{|l|}{ Women occupation } \\
\hline Not working & 1147 & 208 & 1 & & 1 & \\
\hline Working but not paid & 463 & 463 & 0.59 & $0.35-0.99$ & 0.79 & $0.46-1.36$ \\
\hline Working for paid & 557 & 121 & 1.20 & $0.83-1.74$ & 1.08 & $0.73-1.60$ \\
\hline \multicolumn{7}{|l|}{ Number of living children } \\
\hline No child & 23 & 1 & 1 & & 1 & \\
\hline 1-2 child & 703 & 239 & 8.69 & $1.89-40.03$ & 2.68 & $0.40-17.83$ \\
\hline 3-4 child & 652 & 93 & 3.64 & $0.77-17.40$ & 1.35 & $0.19-9.78$ \\
\hline $5+$ child & 769 & 45 & 1.45 & $0.30-6.95$ & 0.89 & $0.10-7.73$ \\
\hline \multicolumn{7}{|l|}{ Decision making } \\
\hline Not participated & 1136 & 136 & 1 & & 1 & \\
\hline Participated & 1031 & 242 & 1.95 & $1.34-2.85$ & 1.40 & $0.90-2.16$ \\
\hline \multicolumn{7}{|l|}{ Fertility Preference } \\
\hline Wants soon & 144 & 7 & 1 & & 1 & \\
\hline Wants later & 1176 & 211 & 3.78 & $1.18-12.10$ & 2.59 & $0.64-10.56$ \\
\hline Wants no more & 749 & 143 & 4.01 & $1.20-13.42$ & $5.90^{*}$ & $1.43-24.44$ \\
\hline undecided & 98 & 17 & 3.69 & $0.93-14.52$ & 4.58 & $1.00-21.02$ \\
\hline \multicolumn{7}{|l|}{ Place of delivery } \\
\hline Home & 2009 & 264 & 1 & & 1 & \\
\hline Health facility & 158 & 115 & 5.53 & $3.68-8.30$ & 0.63 & $0.18-2.19$ \\
\hline
\end{tabular}

\footnotetext{
Skilled attendance at birth
} 
Table 4 Multivariate logistic regression examining factors associated with postpartum contraceptive use in Ethiopia, 2011 ( $n=2545)$ (Continued)

\begin{tabular}{|c|c|c|c|c|c|c|}
\hline \multirow[t]{2}{*}{ Variables } & \multicolumn{2}{|c|}{ PPFP Use } & \multicolumn{4}{|c|}{ OR $(95 \% \mathrm{Cl})$} \\
\hline & No & Yes & $\mathrm{COR}$ & $95 \% \mathrm{Cl}$ & $A O R$ & $95 \% \mathrm{Cl}$ \\
\hline No & 2055 & 301 & 1 & & 1 & \\
\hline Yes & 112 & 77 & 6.13 & $4.24-8.88$ & 2.07 & $0.69-6.24$ \\
\hline \multicolumn{7}{|c|}{ Skilled antenatal care } \\
\hline No & 1564 & 161 & 1 & & 1 & \\
\hline Yes & 603 & 217 & 3.48 & $2.40-5.03$ & 1.16 & $0.72-1.89$ \\
\hline \multicolumn{7}{|c|}{ Skilled postnatal care } \\
\hline No & 2059 & 303 & 1 & & 1 & \\
\hline Yes & 108 & 75 & 4.74 & $3.02-7.45$ & 1.86 & $0.94-3.65$ \\
\hline \multicolumn{7}{|l|}{ Birth order } \\
\hline First & 297 & 96 & 1 & & 1 & \\
\hline $2-3$ & 653 & 195 & 0.93 & $0.60-1.43$ & 1.09 & $0.61-1.94$ \\
\hline $4-5$ & 515 & 50 & 0.31 & $0.17-0.54$ & 0.59 & $0.25-1.41$ \\
\hline $6+$ & 702 & 37 & 0.16 & $0.08-0.30$ & 0.50 & $0.16-1.60$ \\
\hline
\end{tabular}

with a desire to become pregnant again right away. This finding is unsurprising as we would expect greater contraceptive use among women who have already achieved (or possibly surpassed) their desired number of children, particularly when compared with women indicating a desire to have another child soon. However, women in the 2011 sample who wanted to delay (rather than avoid) their next pregnancy were no more likely to use family planning than women who wanted to become pregnant soon. In contrast, in the 2016 sample we see that women with a desire to delay their next pregnancy have more than 4 times the odds of family planning use compared to women who want a pregnancy soon. This suggests that postpartum women in Ethiopia are beginning to use contraception not just to avoid a future pregnancy but also to delay their next pregnancy; this increase in the use of contraception for birth spacing represents great promise in government efforts aimed at achieving optimal birth intervals and addressing unmet need for family planning.

Across both rounds of data collection and in agreement with numerous other studies [18, 31, 32], women's educational status was found to be associated with postpartum contraceptive use. In both samples, women who had at least some primary or secondary education had about twice the odds of contraceptive use as compared to non-educated women. Female education is widely thought to play an important role in fertility [33-35] and these findings support that conclusion.

Finally, this study investigated the association between several key maternal healthcare services and postpartum contraceptive use. Although numerous studies have shown a relationship between the use of some type of maternal healthcare service and postpartum contraceptive utilization, in the 2011 sample of women, these services did not show significant association. While these results may suggest no correlation between skilled maternal healthcare and subsequent postpartum contraceptive use in Ethiopia, we hypothesise two alternative explanations for this finding. First, it is possible that providers were offering family planning information to clients at the time they received one or more types of maternal healthcare services, but the amount or type of information provided may have been insufficient to result in actual contraceptive use. In other words, providers may have done a poor job of discussing information on a variety of methods or may have rushed through the information without verifying that women still recovering from labour and attending to a newborn are fully comprehending their contraceptive options and necessary next steps for obtaining their method of choice. Second, this finding could be the result of poor integration of family planning counselling and services during the provisions of skilled maternal healthcare. Services may be poorly integrated for a variety of reasons. Service providers may be poorly trained on integration protocols or may be simply unable to provide family planning information if experiencing a high case-load of clients. For example, a study in the capital city of Ethiopia showed that nearly two-third of pregnant women accessing antenatal care services did not receive any counselling about contraceptive methods [36]. Further, even those providers who are well-trained may lack sufficient motivation to follow integration protocol unless increased supervision or other accountability mechanisms are in place [37-40]. 
Table 5 Multivariate logistic regression examining factors associated with postpartum contraceptive use in Ethiopia, 2016 $(n=2386)$

\begin{tabular}{|c|c|c|c|c|c|c|}
\hline \multirow[t]{2}{*}{ Variables } & \multicolumn{2}{|c|}{ PPFP Use } & \multicolumn{4}{|c|}{ OR $(95 \% \mathrm{Cl})$} \\
\hline & No & Yes & $\mathrm{COR}$ & $95 \% \mathrm{Cl}$ & $\mathrm{AOR}$ & $95 \% \mathrm{Cl}$ \\
\hline \multicolumn{7}{|l|}{ Wealth index } \\
\hline Low & 933 & 152 & 1 & & 1 & \\
\hline Middle & 383 & 108 & 1.72 & $1.12-2.65$ & 1.45 & $0.90-2.36$ \\
\hline High & 518 & 292 & 3.46 & $2.34-5.09$ & 1.53 & $0.97-2.39$ \\
\hline \multicolumn{7}{|l|}{ Age category (in years) } \\
\hline $15-24$ & 538 & 208 & 1 & & 1 & \\
\hline $25-34$ & 925 & 269 & 0.75 & $0.55-1.03$ & 0.94 & $0.59-1.50$ \\
\hline $35+$ & 371 & 76 & 0.53 & $0.33-0.86$ & 1.18 & $0.57-2.42$ \\
\hline \multicolumn{7}{|l|}{ Residence } \\
\hline Urban & 136 & 152 & 1 & & 1 & \\
\hline Rural & 1698 & 401 & 0.21 & $0.14-0.31$ & 0.56 & $0.27-1.13$ \\
\hline \multicolumn{7}{|c|}{ Access to family planning media } \\
\hline No & 1454 & 352 & 1 & & 1 & \\
\hline Yes & 380 & 200 & 2.17 & $1.54-3.06$ & 0.95 & $0.64-1.40$ \\
\hline \multicolumn{7}{|c|}{ Women educational status } \\
\hline No education & 1203 & 213 & 1 & & 1 & \\
\hline Primary & 523 & 232 & 2.51 & $1.79-3.50$ & 1.32 & $0.90-1.93$ \\
\hline Secondary or above & 107 & 107 & 5.63 & $3.58-8.85$ & $2.03^{*}$ & $1.09-3.78$ \\
\hline \multicolumn{7}{|l|}{ Partner education } \\
\hline No education & 899 & 158 & 1 & & 1 & \\
\hline Primary & 710 & 259 & 2.08 & $1.44-3.02$ & 1.36 & $0.95-1.96$ \\
\hline Secondary or above & 225 & 136 & 3.44 & $2.24-5.30$ & 0.75 & $0.41-1.37$ \\
\hline \multicolumn{7}{|l|}{ Number of living children } \\
\hline No child & 8 & 7 & 1 & & 1 & \\
\hline 1-2 child & 640 & 299 & 0.56 & $0.10-3.12$ & 0.22 & $0.04-1.30$ \\
\hline 3-4 child & 507 & 145 & 0.34 & $0.06-1.82$ & 0.21 & $0.03-1.28$ \\
\hline $5+$ child & 678 & 102 & 0.18 & $0.03-1.02$ & 0.15 & $0.02-1.00$ \\
\hline \multicolumn{7}{|c|}{ Visited by FP worker in the past 12 months } \\
\hline No & 1289 & 319 & 1 & & 1 & \\
\hline Yes & 545 & 233 & 1.73 & $1.24-2.40$ & 1.40 & $0.99-1.99$ \\
\hline \multicolumn{7}{|l|}{ Fertility Preference } \\
\hline Wants soon & 172 & 15 & 1 & & 1 & \\
\hline Wants later & 955 & 343 & 4.23 & $1.70-10.55$ & $4.38^{* *}$ & $1.46-13.18$ \\
\hline Wants no more & 589 & 171 & 3.42 & $1.28-9.09$ & $5.14^{* *}$ & $1.59-16.59$ \\
\hline undecided & 117 & 24 & 2.43 & $0.77-7.67$ & 3.44 & $0.97-12.17$ \\
\hline \multicolumn{7}{|l|}{ Place of delivery } \\
\hline Home & 1289 & 210 & 1 & & 1 & \\
\hline Health facility & 545 & 342 & 3.85 & $2.81-5.23$ & $1.71^{*}$ & $1.12-2.62$ \\
\hline \multicolumn{7}{|l|}{ Skilled attendance at birth } \\
\hline No & 1689 & 436 & 1 & & 1 & \\
\hline Yes & 144 & 117 & 3.15 & $2.15-4.62$ & 1.28 & $0.81-2.01$ \\
\hline
\end{tabular}

Skilled antenatal care 
Table 5 Multivariate logistic regression examining factors associated with postpartum contraceptive use in Ethiopia, 2016 ( $n=2386$ ) (Continued)

\begin{tabular}{|c|c|c|c|c|c|c|}
\hline \multirow[t]{2}{*}{ Variables } & \multicolumn{2}{|c|}{ PPFP Use } & \multicolumn{4}{|c|}{ OR $(95 \% \mathrm{Cl})$} \\
\hline & No & Yes & COR & $95 \% \mathrm{Cl}$ & $\mathrm{AOR}$ & $95 \% \mathrm{Cl}$ \\
\hline Yes & 1128 & 492 & 5.08 & $3.01-8.46$ & $2.41^{* *}$ & $1.41-4.10$ \\
\hline \multicolumn{7}{|c|}{ Skilled postnatal care } \\
\hline No & 1558 & 373 & 1 & & 1 & \\
\hline Yes & 276 & 180 & 2.72 & $1.96-3.75$ & 1.03 & $0.68-1.56$ \\
\hline \multicolumn{7}{|c|}{ Birth order } \\
\hline First & 321 & 159 & 1 & & 1 & \\
\hline $2-3$ & 528 & 221 & 0.85 & $0.58-1.24$ & 1.02 & $0.63-1.64$ \\
\hline $4-5$ & 416 & 94 & 0.46 & $0.30-0.70$ & 0.83 & $0.38-1.81$ \\
\hline $6+$ & 569 & 79 & 0.49 & $0.17-0.46$ & 0.69 & $0.25-1.94$ \\
\hline
\end{tabular}

PPFP Postpartum Family Planning, COR Crude Odds Ratio, AOR Adjusted Odds Ratio ${ }^{* *} p<0.01,{ }^{*} p<0.05$

In contrast to the null findings in our 2011 sample regarding skilled maternal healthcare and postpartum contraceptive use, within our 2016 sample, we found that both delivery within a health care facility and receipt of skilled antenatal care approximately doubled the odds of postpartum contraceptive use. These findings are in line with previous studies investigating the impact of postpartum family planning integration on subsequent contraceptive use [15-19,31]. The fact that these associations did not exist in the 2011 sample lends some weight to our hypothesis that postpartum family planning messages and services were not well integrated in Ethiopia in 2011 compared to 2016. The new associations emerging in the 2016 data suggest that the Ethiopian ministry of health is succeeding in their demonstrated efforts to integrate contraceptive messages and services during the prenatal period as well as at some point before the patient exits the facility after giving birth. In other words, not only are women having more skilled care before, during, and after delivery, our findings suggest that women may also receive more exposure to family planning services during this critical time; It appears that facilities are capitalising on the convenience of reaching women with family planning messaging while they are already at the facility giving birth.

Importantly, despite remarkable progress in postpartum contraceptive use and increased use of skilled maternal healthcare in Ethiopia, there are still large numbers of women giving births at home, without benefit of skilled antenatal care or skilled delivery, and without skilled postnatal care following their birth. These findings suggest the Ethiopian government would benefit from examining the variety of factors that may be keeping skilled care beyond the reach of large numbers of women, for example the quality of family planning counselling provided during outreach to rural women in their residential homes. Currently, the Ethiopian government has an ambitious plan to achieve nearly universal coverage for ante- and postnatal care and skilled birth attendance [25]. There is much progress remaining in obtaining this goal and the government should continue to prioritize and reinforce efforts to expand and improve maternal healthcare, postpartum contraceptive use, and integration of family planning into all reproductive health services.

This study is not without limitations. First, the data used in this analysis are self-reported and therefore may bias results if participants felt the need to alter their responses based on perceived preferences of the enumerators. Second, while participants report on whether or not they received various types of maternal healthcare services, they did not report on the content of those services and - as we suggest above - it may be the case that not all service providers adhere to national guidelines that mandate family planning integration into reproductive healthcare services. Additionally, it is possible that some women may have started a contraceptive method at some point following their most recent birth but may have discontinued that method prior to being interviewed. In this case, it is possible that some women with some postpartum contraceptive use would have been misclassified as non-users. However, the majority of contraceptive users selected injectable contraception which has a duration of three months following each injection; we would not expect discontinuation rates to be high in the short period of time between contraceptive initiation and the date of interview, particularly among those women who did not immediately initiate contraception following birth and/or those whose last birth preceded the interview date by only a few months. In this regard, for instance, the present analysis shows that nearly two thirds of our participants commence contraceptive six months after delivery. Finally, participants vary in terms of the amount of time since their recent 
birth, with the time between birth and interview ranging from one to 12 months. Those with fewer months since their recent birth may differ from those with more distant births, and this heterogeneity may warrant further exploration in subsequent analyses.

\section{Conclusion}

In conclusion, the present study revealed that postpartum contraceptive use in Ethiopia is low but increased between 2011 and 2016. Unsurprisingly, educational obtainment and the desire to avoid future pregnancy were positively associated with postpartum contraceptive use in both survey rounds; however 2016 saw a diminished role of wealth as a key correlate of contraceptive use and an emerging association among women with a desire to delay their next pregnancy. Within our 2011 sample, several key maternal healthcare services such as antenatal care and institutional delivery had no association with postpartum contraceptive use, but these null findings became positive associations in the 2016 sample. These results suggest national efforts to strengthen the integration of family planning counselling and services with skilled maternal healthcare services are succeeding, allowing health care facilities to reduce missed opportunities for increasing contraceptive use among this critical population within Ethiopia. Efforts should continue given the large numbers of women in Ethiopia still delivering at home and without the benefit of skilled pre- and postnatal care.

\begin{abstract}
Abbreviations
AOR: Adjusted odds ratio; Cl: Confidence interval; CPC: Carolina Population Center; CPR: Contraceptive prevalence rate; DHS: Demographic and health survey; EA: Enumeration area; EDHS: Ethiopian demographic and health survey; EHNRI: Ethiopian Health Nutrition Research Institute; FP: Family planning; IUD: Intrauterine device; LAM: Lactational amenorrhea method; NICHD: National Institute of Child Health \& Human Development; NRERC: National Research Ethics Review Committee; PPFP: Postpartum family planning
\end{abstract}

\section{Acknowledgements}

We thank DHS Program for giving us permission to use the EDHS 2011 and EDHS 2016 data for this analysis.

\section{Funding}

We are grateful to the Carolina Population Center (CPC) (R24HD050924) for general support and to a career development grant (4R00HD086270-04) from the National Institute of Child Health \& Human Development (NICHD) to the manuscript's senior author. However, beyond the general and career support to the manuscript's senior author, the funders did not have any role in the design of the study and collection, analysis, and interpretation of data and in writing the manuscript. The contents of this article are solely the responsibility of the authors and do not necessarily represent the official views of CPC or NICHD.

\section{Availability of data and materials}

The datasets used for this study are publicly available from the DHS program website [http://dhsprogram.com/data/].

\section{Authors' contributions}

Initially conceived and designed the study: GAT, TTM and ZBM. Conducted the analysis: GAT. Wrote the paper and made revisions: GAT, KT. Reviewing the manuscript critically: TTM, ZBM. All authors read and approved the manuscript.

\section{Ethics approval and consent to participate}

Authorisation for using the data in the current study was granted from the DHS program upon presenting the aims of the study and the research plan. This analysis uses secondary, de-identified data made publicly available by ICF International and the EDHS. Ethical review for the primary data collection activities conducted by the EDHS was performed by the Review Board of the Ethiopian Health Nutrition Research Institute (EHNRI), the National Research Ethics Review Committee (NRERC) at the Ministry of Science and Technology, the Institutional Review Board of ICF International, and the United States Center for Disease Control. Detailed information on the data collection procedures employed by EHDS has been published as a full report elsewhere $[21,27]$.

\section{Competing interests}

The authors declare that they have no competing interests.

\section{Publisher's Note}

Springer Nature remains neutral with regard to jurisdictional claims in published maps and institutional affiliations.

\section{Author details}

'Department of Reproductive Health, Institute of Public Health, University of Gondar, Gondar, Ethiopia. ${ }^{2}$ School of Public Health, The University of Adelaide, Adelaide, Australia. ${ }^{3}$ Department of Midwifery, Tseda Health Science College, Gondar, Ethiopia. ${ }^{4}$ Centre for Health Research, Western Sydney University, Sydney, Australia. ${ }^{5}$ Department of Maternal and Child Health, Gillings School of Global Public Health, University of North Carolina at Chapel Hill, Chapel Hill, USA.

Received: 1 September 2016 Accepted: 26 April 2018

Published online: 16 May 2018

\section{References}

1. Ahmed S, Ahmed S, McKaig C, Begum N, Mungia J, Norton M, Baqui AH. The effect of integrating family planning with a maternal and newborn health program on postpartum contraceptive use and optimal birth spacing in rural Bangladesh. Stud Fam Plan. 2015:46(3):297-312.

2. Rutstein SO, Winter R. The effects of fertility behavior on child survival and child nutritional status: evidence from demographic and health surveys, 2006-2012. In: DHS Analystical studies no 37. Rockville: ICF International; 2014.

3. World Health Organization (WHO). Report of a WHO technical consultation on birth spacing. Geneva: WHO; 2005

4. Cleland J, Bernstein S, Ezeh A, Faundes A, Glasier A, Innis J. Family planning: the unfinished agenda. Lancet. 2006;368(9549):1810-27.

5. Rutstein SO. Further evidence of the effects of preceding birth intervals on neonatal, infant, and under-five-years mortality and nutritional status in developing countries: evidence from the demographic and health surveys. DHSWorking papers no. 41. Calverton: Macro International; 2008.

6. Zhu BP, Rolfs RT, Nangle BE, Horan JM. Effect of the interval between pregnancies on perinatal outcomes. N Engl J Med. 1999;340(8):589-94.

7. DaVanzo J, Hale L, Razzaque A, Rahman M. The effects of pregnancy spacing on infant and child mortality in Matlab, Bangladesh: how they vary by the type of pregnancy outcome that began the interval. Popul Stud. 2008:62(2):131-54

8. Conde-Agudelo A, Rosas-Bermudez A, Kafury-Goeta AC. Effects of birth spacing on maternal health: a systematic review. Am J Obstet Gynecol. 2007;196(4):297-308.

9. Cleland J, Conde-Agudelo A, Peterson H, Ross J, Tsui A. Contraception and health. Lancet. 2012;380(9837):149-56

10. Tegegn M, Arefaynie M, Tiruye TY. Unmet need for modern contraceptives and associated factors among women in the extended postpartum period in Dessie town, Ethiopia. Contracept Reprod Med. 2017;2:21.

11. Ross JA, Winfrey WL. Contraceptive use, intention to use and unmet need during the extended postpartum period. Int Fam Plan Perspect. 2001;27(1):20-7

12. MacQuarrie Kerry LD. Unmet need for family planning among young women: levels and trends. DHS comparative reports no. 34. Rockville: ICF International; 2014. 
13. Gaffield ME, Egan S, Temmerman M. It's about time: WHO and partners release programming strategies for postpartum family planning. Glob Health Sci Pract. 2014;2(1):4-9.

14. Do M, Hotchkiss D. Relationships between antenatal and postnatal care and post-partum modern contraceptive use: evidence from population surveys in Kenya and Zambia. BMC Health Serv Res. 2013;13:6.

15. Abera Y, Mengesha ZB, Tessema GA. Postpartum contraceptive use in Gondar town, Northwest Ethiopia: a community based cross-sectional study. BMC Womens Health. 2015;15:19.

16. Achyut $P$, Mishra A, Montana L, Sengupta R, Calhoun LM, Nanda P. Integration of family planning with maternal health services: an opportunity to increase postpartum modern contraceptive use in urban Uttar Pradesh, India. J Fam Plann Reprod Health Care. 2016;42(2):107-15.

17. Akinlo A, Bisiriyu A, Esimai O. Influence of use of maternal health care on postpartum contraception in Nigeria. DHSWorking papers no. 92. Calverton: ICF International; 2013

18. Rutaremwa G, Kabagenyi A, Wandera SO, Jhamba T, Akiror E, Nviiri HL. Predictors of modern contraceptive use during the postpartum period among women in Uganda: a population-based cross sectional study. BMC Public Health. 2015;15:262.

19. Tappis H, Kazi A, Hameed W, Dahar Z, Ali A, Agha S. The role of quality health services and discussion about birth spacing in postpartum contraceptive use in Sindh, Pakistan: a multilevel analysis. PLoS One. 2015; 10(10):e0139628

20. Teklehaimanot HD, Teklehaimanot A. Human resource development for a community-based health extension program: a case study from Ethiopia. Hum Resour Health. 2013;11:39.

21. CSA [Ethiopia] and ICF International. Ethiopia demographic and health survey 2016. Addis Ababa and Rockville: CSA [Ethiopia] and ICF International; 2016.

22. Ethiopia: Commitment Maker Since 2012 [http://www.familyplanning2020 org/entities/56]

23. Ethiopia Ministry of Health. National Guideline for family planning Services in Ethiopia. Addis Ababa: Federal Democratic Republic of Ethiopia Ministry of Health; 2011.

24. FMOH. Health sector transformation plan (HSTP) 2015/16 - 2019/20. Addis Ababa: Federal Ministry of Health (FMOH); 2015.

25. FMOH. Draft National Reproductive Health Strategy (2016 - 2020). Addis Ababa: Federal Ministry of Health (FMOH); 2016.

26. The DHS data collection [http://dhsprogram.com/data/data-collection.cfm]

27. Central Statistics Agency (CSA) of Ethiopia and ICF International. Ethiopian demographic and health survey report 2011. Addis Ababa, Ethiopia and Calverton: Central Statistical Agency and ICF International; 2012.

28. Wilopo SA, Setyawan A, Pinandari AW, Prihyugiarto T, Juliaan F, Magnani RJ. Levels, trends and correlates of unmet need for family planning among postpartum women in Indonesia: 2007-2015. BMC Womens Health. 2017; 17(1):120.

29. Population Reference Bureau (PRB): Family planning worldwide 2013 data. Washington DC: PRB; 2013. https://www.prb.org/family-planning-worldwide2013/.

30. Kandala NB, Lukumu FK, Mantempa JN, Kandala JD, Chirwa T. Disparities in modern contraception use among women in the democratic republic of Congo: a cross-sectional spatial analysis of provincial variations based on household survey data. J Biosoc Sci. 2015;47(3):345-62.

31. Abraha TH, Teferra AS, Gelagay AA. Postpartum modern contraceptive use in northern Ethiopia: prevalence and associated factors. Epidemiol Health. 2017;39:e2017012

32. Mahmood SE, Srivastava A, Shrotriya VP, Shaifali I, Mishra P. Postpartum contraceptive use in rural Bareilly. Indian J Commun Health. 2011:23(2):56-7.

33. Hahn Y, Islam A, Nuzhat K, Smyth R, Yang H-S. Education, marriage and fertility: long-term evidence from a female stipend program in Bangladesh. Melbourne: Monash University; 2015.

34. Becker SO, Cinnirella F, Woessmann L. Does women's education affect fertility? Evidence from pre-demographic transition Prussia. Eur Rev Econ Hist. 2013;17(1):24-44.

35. Lam D, Sedlacek G, Duryea S. Increase in women' s education and fertility decline in Brazil. Anais. 2016:89-118.

36. Teshome A, Birara M, Rominski SD. Quality of family planning counseling among women attending prenatal care at a hospital in Addis Ababa, Ethiopia. Int J Gynaecol Obstet. 2017:137(2):174-9.
37. Das J, Hammer J, Leonard K. The quality of medical advice in low-income countries. J Econ Perspect. 2008:22(2):93-114.

38. Mohanan M, Vera-Hernandez M, Das V, Giardili S, Goldhaber-Fiebert JD, Rabin TL, Raj SS, Schwartz JI, Seth A. The know-do gap in quality of health care for childhood diarrhea and pneumonia in rural India. JAMA Pediatr. 2015;169(4):349-57.

39. Tumlinson K, Okigbo CC, Speizer IS. Provider barriers to family planning access in urban Kenya. Contraception. 2015;92(2):143-51.

40. Tumlinson K, Speizer IS, Curtis SL, Pence BW. Accuracy of standard measures of family planning service quality: findings from the simulated client method. Stud Fam Plan. 2014:45(4):443-70.

\section{Ready to submit your research? Choose BMC and benefit from:}

- fast, convenient online submission

- thorough peer review by experienced researchers in your field

- rapid publication on acceptance

- support for research data, including large and complex data types

- gold Open Access which fosters wider collaboration and increased citations

- maximum visibility for your research: over $100 \mathrm{M}$ website views per year

At BMC, research is always in progress.

Learn more biomedcentral.com/submissions 